\title{
Evaluation of a Transumbilical Incision as an Approach for Organ Removal in Laparoscopy-assisted Colectomy
}

\author{
KODAI TOMIOKA, MASAHIKO MURAKAMI, MAKOTO WATANABE, AKIRA FUJIMORI, \\ TOMOTAKE KOIZUMI, SATORU GOTO, KOJI OTSUKA and TAKESHI AOKI
}

Division of Gastroenterological and General Surgery, Department of Surgery, Showa University, Tokyo, Japan

\begin{abstract}
Aim: To investigate the risk factors of transumbilical incision for organ removal in laparoscopyassisted colectomy (LAC). Patients and Methods: We enrolled 348 consecutive patients who underwent LAC at our hospital between 2010 and 2013. The occurrence of superficial surgical site infection (SSI) and hernia at the transumbilical port site were recorded. Results: SSI was observed in 15 patients $(4.31 \%)$; there were no obvious associated risk factors. Hernia occurred in 23 patients (6.61\%); multivariate analysis revealed that female sex [odds ratio $(O R)=4.736$, 95\% confidence interval $(C I)=1.058$ to 24.362; $p=0.042]$ and diabetes mellitus (OR=4.655, 95\% CI=1.520 to 13.585; $p=0.004)$ were significantly associated with the risk of hernia. Anastomotic method and the anastomotic site (inside and outside the body) did not contribute to the occurrence of complications. Conclusion: Female sex and diabetes mellitus are independent risk factors for hernia formation in patients undergoing transumbilical incision for organ removal in laparoscopy-assisted colectomy.
\end{abstract}

In laparoscopic surgery, a transumbilical incision is often used for anastomosis and organ removal. In our Department, we have been performing transumbilical incisions to remove resected organs since shortly after the introduction of laparoscopic surgery. We vertically extend the umbilical wound corresponding to the size of the specimen and anastomose extracorporeally. We have already reported that surgical site infection (SSI) and hernia occurred at a significantly higher rate in colorectal resection than in gastric

This article is freely accessible online.

Correspondence to: Kodai Tomioka, Division of Gastroenterological and General Surgery, Department of Surgery, Showa University, 1-5-8 Hatanodai, Shinagawa, Tokyo 142-8666, Japan. Tel: +81 337848541, Fax: +81 337845835, e-mail: tomioka@med.showa-u.ac.jp

Key Words: Transumbilical wound, complication, laparoscopic, surgery. resection in laparoscopic surgery. Additionally, we showed that female sex and diabetes mellitus (DM) were independent risk factors in relation to hernia (1).

The present study aimed to evaluate the complication rates and risk factors associated with transumbilical incisions in laparoscopy-assisted colectomy (LAC).

\section{Patients and Methods}

This study included a cohort of 417 consecutive patients who underwent LAC for colorectal cancer at the Division of Gastroenterological and General Surgery, Department of Surgery, Showa University Hospital, Japan, between January 2010 and December 2013. The exclusion criteria were as follows: reoperation in the early postoperative period, follow-up by other hospitals from the early postoperative period, conversion to laparotomy, multiple simultaneous procedures, and unknown details regarding the anastomosis. Of the 417 patients, 69 were excluded. The study protocol was approved by the Showa University Institutional Review Board (approval number: 1917), University Hospital Medical Information Network (UMIN) ID: 000021651.

Patient data, including sex, age, height, weight, body mass index (BMI), history of DM, type of anastomosis [functional end-to-end anastomosis (FEEA), double-staple technique (DST), and hand-sewn end-to-end anastomosis (HEEA)], anastomotic point (extracorporeal and intracorporeal), type of surgery, surgical duration, amount of blood loss, maximum tumor diameter, intraoperative accident, SSI, umbilical wound port-site hernia, and length of postoperative hospital stay, were collected from the hospital database. Additionally, we retrospectively examined transumbilical wound SSI, hernia rate and risk factors associated with transumbilical incision.

SSI was defined according to the criteria of the American College of Surgeons National Surgical Quality Improvement Program (2). Wound hernia was defined according to the definition by Tonouchi et al. (3). We followed-up patients every 3 months in the first postoperative year and yearly thereafter for 3 years. SSIs were monitored by the Infection Control Team of our hospital, and umbilical port-site hernias were routinely assessed according to computed tomography (CT) and clinical findings. Patients with DM were allowed to undergo diabetes assessments preoperatively and were operated on under glycemic control.

In all cases, preoperative mechanical bowel preparation was performed, and a second-generation cephalosporin was administered intravenously 30 minutes before surgery. Additionally, wound 
closure methods and covering methods were performed following a standardized protocol at our Department. We cut the skin in a craniocaudal direction from the center of the navel and inserted the first 12-mm port via the closed method (Figure 1a).

The umbilical wound was extended in the craniocaudal direction to account for the size of the resected organ (approximately $3-5 \mathrm{~cm}$ ) (Figure 1b), and a wound protector was attached to extract the specimen (Figure 1c and d). An appropriate anastomosis method was selected based on the type of operation. FEEA was carried out using an automatic suture instrument, and HEEA was performed using the Gambee anastomosis method with a 3-0 absorbable thread. An automatic anastomotic device was used for DST.

The anterior and posterior laminae of the rectal sheath on the wound were continuously sutured with a monofilament absorbable suture material. All wounds were washed with $50 \mathrm{ml}$ saline, and buried interrupted dermal sutures were performed using a 4-0 monofilament absorbable suture material. We used silver and hydrocolloid dressing to prevent superficial SSI, and the wound was sealed for 48 hours postoperatively (Figure 1e and f).

Data are presented as mean \pm standard deviation (SD) unless otherwise specified. Risk factors were investigated using univariate analyses, including the chi-squared test, Fisher's exact test, Wilcoxon rank-sum test, Wilcoxon signed-rank test, and univariate logistic regression. Significant variables were then analyzed using multivariate logistic regression analysis. All analyses were performed using JMP 12 (SAS Institute Inc., Cary, NC, USA). Statistical assessments were two-sided, and a $p$-value of less than 0.05 was considered to indicate significance.

\section{Results}

Of the total 348 patients, 200 were male $(57.5 \%)$ and 148 were female $(42.5 \%)$, with a mean \pm SD age of $69.09 \pm 11.71$ years (median, 71 years; range, 22-91 years). The details of anastomosis for each procedure are shown in Table I.

SSI was observed in 15 patients $(4.31 \%)$. In the univariate analysis comparing groups with and without SSI, there were no significant differences, except for the duration of postoperative hospital stay, which, as would be expected, was significantly longer in patients with SSI (Table II).

An umbilical wound hernia was observed in 23 patients $(6.61 \%)$. The median time to hernia development was 12 months (range $=3-24$ months). On comparing the groups with and without umbilical wound hernia, there were significant differences in weight $(p=0.014)$, BMI $(p<0.001)$, DM $(p=0.004)$, and blood loss $(p=0.002)$, whereas there was no significant difference in sex $(p=0.081)$ (Table III). In multivariate analysis, female sex [odds ratio $(\mathrm{OR})=4.736,95 \%$ confidence interval $(\mathrm{CI})=1.058$ to $24.362 ; p=0.042]$ and DM $(\mathrm{OR}=4.655,95 \% \mathrm{CI}=1.520$ to $13.585 ; p=0.004)$ were significantly associated with increased risk of hernia (Table IV).

\section{Discussion}

An umbilical incision has been commonly used in laparoscopic surgery recently. Although a transumbilical incision is generally avoided because of the possibility of SSI and postoperative
Table I. Surgical procedure and anastomotic methods used in transumbilical incision approach for laparoscopy-assisted colectomy.

\begin{tabular}{lcc}
\hline Procedure & $\begin{array}{c}\text { Number of } \\
\text { patients }\end{array}$ & $\begin{array}{c}\text { Anastomosis: } \\
\text { FEEA/HEEA/DST }\end{array}$ \\
\hline Ileocecal resection & 29 & $29 / 0 / 0$ \\
Right colon resection & 60 & $60 / 0 / 0$ \\
Right hemicolectomy & 32 & $32 / 0 / 0$ \\
Transverse partial resection & 15 & $13 / 2 / 0$ \\
Left hemicolectomy & 1 & $1 / 0 / 0$ \\
Left colon resection & 24 & $20 / 3 / 1$ \\
Sigmoid colectomy & 81 & $25 / 2 / 54$ \\
High anterior resection & 35 & $0 / 0 / 35$ \\
Low anterior resection & 71 & $0 / 0 / 71$ \\
\hline Total & 348 \\
\hline
\end{tabular}

FEEA, Functional end-to-end anastomosis; HEEA, hand-sewn end-toend anastomosis; DST, double-staple technique.

adhesion, it was shown not to be associated with complications (4). In our Department, we have used a transumbilical incision routinely in all abdominal surgeries considering it to have the following advantages: (a) better cosmetic outcomes and ease of extension, (b) ability to minimize the skin incision, and (c) ability to reach the abdominal cavity safely and securely via the shortest anatomical distance.

With regard to wound extension, if fasciotomy is carried out completely, it is possible to extract large specimens by utilizing the extensibility of the skin in the umbilicus, without excessive skin incision. Thus, it is considered that a transumbilical incision is rational and provides an excellent esthetic outcome.

We have already reported that we found SSI to occur at a significantly higher rate in colorectal resection than in gastric resection (1), and the most likely cause is bacterial contamination at extracorporeal manipulation for resection and anastomosis. In this study, we limited the procedure to LAC and included the anastomotic method (FEEA, HEEA, and DST) and anastomotic site (inside and outside the body) as evaluated variables. Additionally, we investigated the usefulness of the wound for organ removal and examined the risk factors for complications. The anastomotic methods differed as FEEA and HEEA were extra-abdominal procedures, and DST was an intra-abdominal procedure.

Umbilical port-site SSI has been reported to occur at rates of 1.06-25.9\% (5-9). Laparoscopic procedures were found to reduce the incidence of port-site infections and other woundrelated complications (10). The risk factors for SSI limited to laparoscopic colon resection have been reported to include increased BMI and a history of DM (11-13). Wound retractors can prevent infection after laparoscopic colorectal procedures, indicating that the methods and instruments used are important $(14,15)$. In our department, the incidence of 


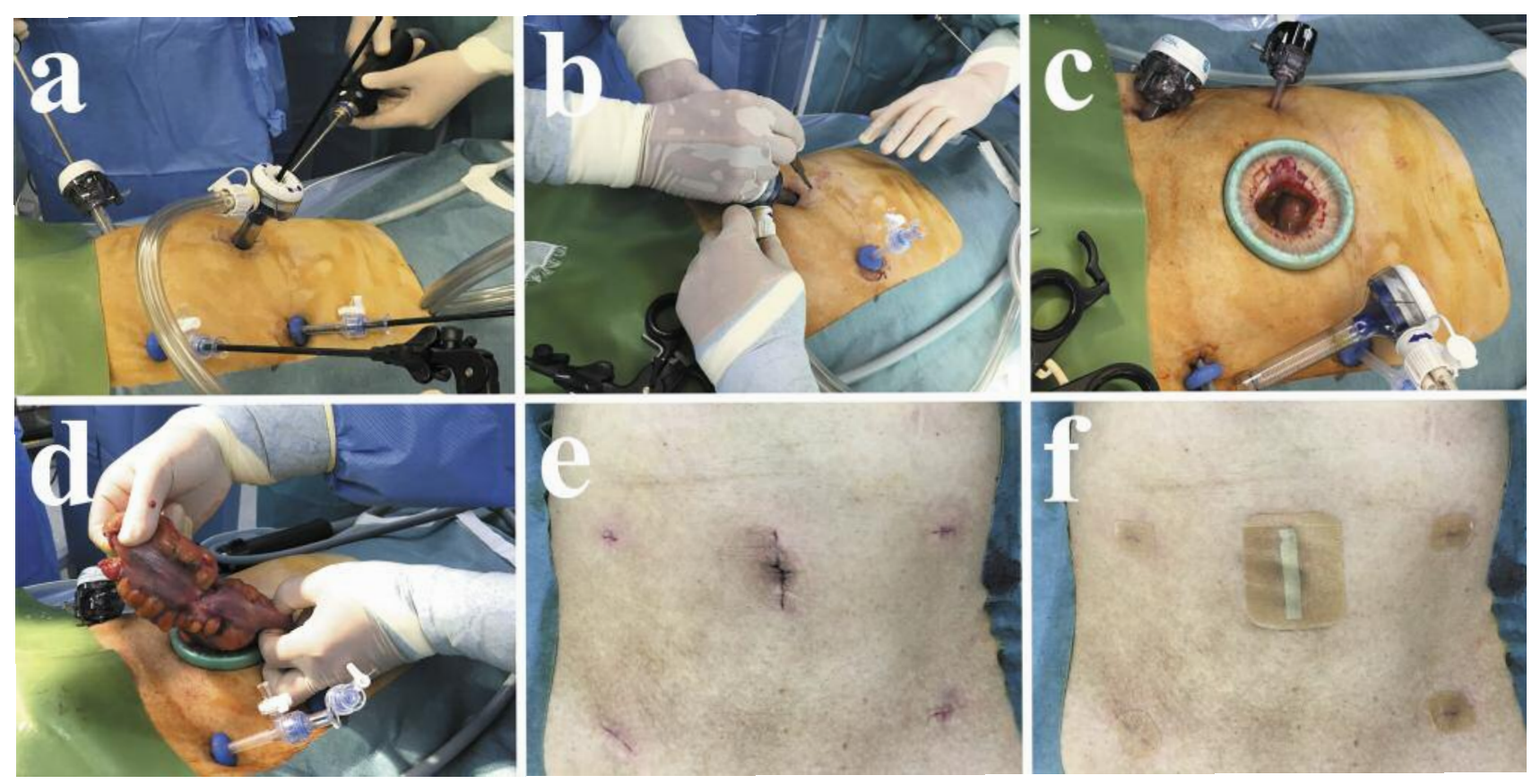

Figure 1. Transumbilical wound. a: Intraoperative insertion of a 12-mm port through the transumbilical wound. $b:$ The wound is cut and extended to enable removal of the organ. $c$ : The wound protector is attached. $d$ : The resected specimen is removed.e: The wound after closure.f: The wound is covered with silver ion and hydrocolloid dressing.

Table II. Demographic data of patients with and without transumbilical wound surgical site infection (SSI) after laparoscopy-assisted colectomy with transumbilical incision approach.

\begin{tabular}{|c|c|c|c|c|}
\hline Variable & & No SSI $(n=333)$ & SSI $(n=15)$ & $p$-Value \\
\hline Age (years) & Mean \pm SD & $69.18 \pm 11.59$ & $67.60 \pm 13.85$ & 0.863 \\
\hline Gender & Male:female & $191: 142$ & $9: 6$ & $>0.999$ \\
\hline Height $(\mathrm{cm})$ & Mean \pm SD & $159.29 \pm 9.60$ & $159.73 \pm 8.20$ & 0.780 \\
\hline Weight (kg) & Mean \pm SD & $57.46 \pm 11.54$ & $57.46 \pm 11.20$ & 0.661 \\
\hline BMI $\left(\mathrm{kg} / \mathrm{m}^{2}\right)$ & Mean \pm SD & $22.53 \pm 3.54$ & $21.97 \pm 3.50$ & 0.579 \\
\hline $\mathrm{DM}$ & $\mathrm{N}(\%)$ & $34(10.21 \%)$ & $1(6.67 \%)$ & $>0.999$ \\
\hline Anastomosis method & FEEA/DST/HEEA & $171 / 156 / 6$ & $9 / 5 / 1$ & 0.292 \\
\hline Anastomotic point & Intra/extra & $158 / 175$ & $5 / 10$ & 0.306 \\
\hline Operative time (min) & Mean \pm SD & $173.53 \pm 67.54$ & $175.00 \pm 58.52$ & 0.712 \\
\hline Blood loss $(\mathrm{g})$ & Mean \pm SD & $38.88 \pm 115.12$ & $111.00 \pm 213.26$ & 0.209 \\
\hline Tumor major axis (mm) & Mean \pm SD & $38.44 \pm 22.32$ & $41.93 \pm 29.72$ & 0.780 \\
\hline Intraoperative accident & $\mathrm{N}(\%)$ & $4(1.20 \%)$ & $0(0 \%)$ & $>0.999$ \\
\hline Postoperative complication & $\mathrm{N}(\%)$ & $35(10.51 \%)$ & $3(20.00 \%)$ & 0.218 \\
\hline Hospital stay (days) & Mean \pm SD & $13.86 \pm 11.89$ & $18.60 \pm 7.74$ & $<0.001$ \\
\hline
\end{tabular}

BMI: Body mass index; DM: diabetes mellitus; FEEA/DST/HEEA: functional end-to-end anastomosis/ double staple teqnique/ hand-sewn end-toend anastomosis; SSI: surgical site infection.

transumbilical wound SSI in LAC was $4.3 \%$ (15/348). There were no significant differences between the groups with and without SSI, and there were no obvious risk factors observed in the present study.
The incidence of a port-site hernia has been reported, with rates of $0-5.2 \%(6), 0.4 \%$ (5), $1.06 \%$ (8), $1.4 \%$ (7), and $25.9 \%$ (9). Nassar et al. observed that extension of the umbilical wound was the most significant risk factor (16). In 
Table III. Demographic data of patients with and without a transumbilical wound hernia after laparoscopy-assisted colectomy with transumbilical incision approach.

\begin{tabular}{|c|c|c|c|c|}
\hline \multicolumn{2}{|l|}{ Variable } & \multirow{2}{*}{$\begin{array}{c}\text { No wound hernia }(n=325) \\
69.21 \pm 11.69\end{array}$} & \multirow{2}{*}{$\begin{array}{c}\text { Wound hernia }(\mathrm{n}=23) \\
67.87 \pm 12.07\end{array}$} & \multirow{2}{*}{$\frac{p \text {-Value }}{0.522}$} \\
\hline Age (years) & Mean \pm SD & & & \\
\hline Gender & Male:female & 191:134 & $9: 14$ & 0.081 \\
\hline Height $(\mathrm{cm})$ & Mean \pm SD & $159.43 \pm 9.53$ & $157.30 \pm 9.65$ & 0.249 \\
\hline Weight $(\mathrm{kg})$ & Mean \pm SD & $56.96 \pm 11.44$ & $63.27 \pm 11.19$ & 0.014 \\
\hline BMI $\left(\mathrm{kg} / \mathrm{m}^{2}\right)$ & Mean \pm SD & $22.28 \pm 3.45$ & $25.49 \pm 3.33$ & $<0.001$ \\
\hline $\mathrm{DM}$ & $\mathrm{N}(\%)$ & $28(8.62 \%)$ & $7(30.43 \%)$ & 0.004 \\
\hline Anastomosis method & FEEA/DST/HEEA & $170 / 149 / 6$ & $10 / 12 / 1$ & 0.555 \\
\hline Anastomotic point & Intra/extra & $151 / 174$ & $12 / 11$ & 0.668 \\
\hline SSI & $\mathrm{N}(\%)$ & $14(4.31 \%)$ & $1(4.35 \%)$ & 1.000 \\
\hline Operative time $(\mathrm{min})$ & Mean \pm SD & $172.83 \pm 67.50$ & $184.34 \pm 61.56$ & 0.170 \\
\hline Blood loss (g) & Mean \pm SD & $39.89 \pm 122.31$ & $71.70 \pm 104.88$ & 0.002 \\
\hline Tumor major axis (mm) & $\mathrm{N}(\%)$ & $38.62 \pm 22.92$ & $38.26 \pm 19.12$ & 0.853 \\
\hline Intraprocedure events & $\mathrm{N}(\%)$ & $4(1.23 \%)$ & $0(0 \%)$ & 1.000 \\
\hline Postoperative complication & $\mathrm{N}(\%)$ & $37(11.38 \%)$ & $1(4.35 \%)$ & 0.491 \\
\hline
\end{tabular}

BMI: Body mass index; DM: diabetes mellitus; FEEA/DST/HEEA: functional end-to-end anastomosis/ double staple technique/ hand-sewn endto-end anastomosis; SSI: surgical site infection.

addition, Comajuncosas et al. pointed out that DM, SSI, wound size, and higher BMI were risk factors for hernia formation, although their research was limited to cholecystectomies (9).

In the present study, an umbilical port-site hernia was noted in 23 out of 348 patients $(6.61 \%)$. Univariate analysis for port-site hernia indicated a greater risk was associated with increased weight $(p=0.014)$, increased BMI $(p<0.001)$, a history of DM $(p=0.004)$, and increased blood loss $(p=0.002)$. The female count was high in the hernia group; however, no significant result was obtained ( $p=0.081)$. As female sex was identified as a risk factor in our previous study, multivariate analysis was performed. The multivariate analysis revealed that female sex $(O R=4.736)$ and $D M$ $(\mathrm{OR}=4.655)$ contributed to the risk of developing a hernia.

We had previously reported that there were no obvious risk factors for SSI and that female sex $(O R=5.410)$ and $D M$ $(\mathrm{OR}=4.437)$ were believed to be risk factors for developing a hernia (1). Owing to the richness of subcutaneous fat in women, suturing a transumbilical wound can be difficult. Thus, technical factors are involved. With regard to the influence of BMI as an index of obesity, we compared the BMI in women with and without hernias, and the BMIs were 25.32 \pm 3.27 and $22.38 \pm 3.50 \mathrm{~kg} / \mathrm{m}^{2}$, respectively $(p=0.0023)$. However, the direct relationship between subcutaneous fat and BMI remains unknown, and we look forward to a further study to evaluate this relationship. In the present study, female sex and DM were identified as risk factors for a transumbilical wound hernia in multivariate analysis, regardless of the surgical procedure.

Conversely, in order to consider the influence of contaminating bacteria and other factors, anastomotic
Table IV. Multivariate ambos of risk of transumbilical wound hernia after laparoscopy-assisted colectomy with transumbilical incision approach.

\begin{tabular}{llccc}
\hline Variable & & OR & $95 \%$ CI & $p$-Value \\
\hline Gender & Female $v s$. male & 4.736 & $1.058-24.362$ & 0.042 \\
Weight & Per kg increase & 1.032 & $0.882-1.063$ & 0.495 \\
BMI & Per kg $/ \mathrm{m}^{2}$ increase & 1.147 & $0.680-1.109$ & 0.264 \\
DM & With $v s$. without & 4.655 & $1.520-13.585$ & 0.008 \\
Blood loss & Per g increase & 1.001 & $0.996-1.002$ & 0.234 \\
\hline
\end{tabular}

CI, Confidence interval; DM: diabetes mellitus; OR, odds ratio.

method and anastomotic site were added to the evaluation; however, no significant difference was observed. Based on the above findings and our previous report, it would seem that colorectal resection itself might be a risk factor for transumbilical wound complications.

The main features of this research are as follows. Firstly, the focus of this study was transumbilical incision as a site for organ removal rather than just a port wound. All specimens were removed through the transumbilical incision, and we extended the wound craniocaudally as necessary. Thus, a further incision for organ removal was not required. Furthermore, we believe that these research findings might suggest the utility of this type of incision in any laparoscopic surgery for all organs. Secondly, we examined and limited LAC to patients with malignant diseases. We routinely performed the operation with lymphadenectomy for 
colorectal malignant disease, regardless of the disease stage. The surgeons had at least 5 years of postgraduate experience, with the possibility of minimal selection bias by the surgeons. Owing to the strict postoperative follow-up, there was minimal loss of data. Thirdly, all procedures from transumbilical incision to wound coating, including all methods of colectomy and perioperative management, were standardized at our Department through an operation manual, thereby minimizing variation and bias.

The present study has several limitations. Firstly, this was a retrospective study. The wound length in each case was unknown, and there was bias in variable settings. Secondly, the low incidence of and a small number of adverse events indicate that we cannot exclude the possibility of a type 2 error. Thirdly, our Institution shifted to laparoscopic surgery in 2010; therefore, we were unable to perform a comparison with open surgery.

In conclusion, female sex and DM are independent risk factors for hernia formation after transumbilical incision approach for LAC. Additionally, anastomosis methods and the anastomotic site (intra/extra-abdominal) did not contribute to the occurrence of complications. In modern laparoscopic surgery, our approach using transumbilical incision with organ removal, including wound closure and covering methods, can be considered a feasible and safe approach with good tolerability and rationality.

\section{Compliance with Ethical Standards}

Informed consent: Informed consent was obtained from all individual participants included in the study. The Authors thank the patients for allowing us to publish this study.

\section{Conflicts of Interest}

None of the Authors has any conflict of interest to declare in regard to this study.

\section{Ethical Approval}

All procedures performed in studies involving human participants were in accordance with the ethical standards of the institutional and/or national research committee and with the 1964 Helsinki declaration and its later amendments or comparable ethical standards. The study protocol was approved by the Showa University Institutional Review Board (Approval number: 1917). University Hospital Medical Information Network (UMIN) ID: 000021651 .

\section{References}

1 Tomioka K, Murakami M, Fujimori A, Watanabe M, Koizumi T, Goto S, Otsuka K and Aoki T: Risk factors for transumbilical wound complications in laparoscopic gastric and colorectal surgery. In Vivo 31: 943-948, 2017.
2 Horan TC, Gaynes RP, Martone WJ, Jarvis WR and Emori TG: CDC definitions of nosocomial surgical site infections, 1992: a modification of CDC definitions of surgical wound infections. Am J Infect Control 20: 271-274, 1992.

3 Tonouchi H, Ohmori Y, Kobayashi M and Kusunoki M: Trocar site hernia. Arch Surg 139: 1248-1256, 2004.

4 Paes TRF, Stroker DL, Ng T and Morecroft J: Circumumbilical versus transumbilical abdominal incision. Br J Surg 74: 822-823, 1987.

5 Lal P, Vindal A, Sharma R, Chander J and Ramteke VK: Safety of open technique for trocar first placement in laparoscopic surgery: a series of 6.000 patients. Surg Endosc 26: 182-188, 2012.

6 Swank HA, Mulder IM, la Chapelle CF, Reitsma JB, Lange JF and Bemelman WA: Systematic review of trocar site hernia. Br J Surg 99: 315-323, 2012.

7 Weiss HG, Brunner W, Biebl MO, Schirnhofer J, Pimpl K, Mittermair C, Obrist C, Brunner E and Hell T: Wound complications in 1145 consecutive transumbilical single-incision laparoscopic procedures. Ann Surg 259: 89-95, 2014.

8 Morita Y, Yamaguchi S, Ishii T, Tashiro J, Kondo H, Suzuki A, Hara K and Koyama I: Does transumbilical incision increase incisional hernia at the extraction site of laparoscopic anterior resection? Am J Surg 209: 1048-1052, 2015.

9 Comajuncosas J, Hermoso J, Gris P, Jimeno J, Orbeal R, Vallverdú H, López Negre JL, Urgellés J, Estalella L and Parés D: Risk factors for umbilical trocar site incisional hernia in laparoscopic cholecystectomy: a prospective 3-year follow-up study. Am J Surg 207: 1-6, 2014.

10 Targarona EM, Balague $\mathrm{C}$, Knook MM and Trías M: Laparoscopic surgery and surgical infection. Br J Surg 87: 536$544,2000$.

11 Aimaq R, Akopian G and Kaufman HS: Surgical site infection rates in laparoscopic versus open colorectal surgery. Am Surg 77: 1290-1204, 2011.

12 Anannamcharoen S, Vachirasrisirikul S and Boonya-Assadorn $\mathrm{C}$ : Incisional surgical site infection in colorectal surgery patients. J Med Assoc Thai 95: 42-47, 2012.

13 Kiran RP, El-Gazzaz GH and Vogel JD and Remzi FH: Laparoscopic approach significantly reduces surgical site infections after colorectal surgery: data from National Surgical Quality Improvement Program. J Am Coll Surg 211: 232-238, 2010.

14 Horiuchi T, Tanishima H, Tamagawa K, Sakaguchi S, Shono Y, Tsubakihara H, Tabuse $\mathrm{K}$ and Kinoshita Y: A wound protector shields incision sites from bacterial invasion. Surg Infect 11: 501-503, 2010.

15 Reid K, Pockney P, Draganic B and Smith SR: Barrier wound protection decreases surgical site infection in open elective colorectal surgery: A randomized clinical trial. Dis Colon Rectum 53: 1374-1380, 2010.

16 Nassar AH, Ashkar KA, Rashed AA and Abdulmoneum MG: Laparoscopic cholecystectomy and the umbilicus. Br J Surg 84 : 630-633, 1997.
Received October 22, 2017

Revised November 7, 2017

Accepted November 13, 2017 